$\xi=-1$

\title{
Design and implementation of smart uninterruptable power supply using battery storage and photovoltaic arrays
}

\author{
S. Narasimha ${ }^{1}$, Surender Reddy Salkuti ${ }^{2 *}$ \\ ${ }^{1}$ Department of Electrical and Electronics Engineering, TKR College of Engineering \& Technology, Hyderabad, India \\ ${ }^{2}$ Department of Railroad and Electrical Engineering, Woosong University, Daejeon, Republic of Korea \\ *Corresponding author E-mail: surender@wsu.ac.kr
}

\begin{abstract}
The objective of this paper is to provide an uninterruptable power supply to the customers by selecting the supply from various reliable power sources such as solar photovoltaic, AC mains and battery storage systems. Initially, the load gets power supply from the reliable source (such as solar photovoltaic), if in case it is unavailable, then the proposed modules automatically switch over to the next reliable source (such as AC mains), and so on. If in case all proposed renewable energy sources (RESs) are unavailable than the proposed module automatically switch over to the local grid supply, if suppose the local grid supply is also unavailable then the proposed module automatically switch over to the power storage bank. Therefore, the proposed intelligent/smart power module can improve the system performance and efficiency. The programming instruction of controller, the relay driver switches appropriate relay of sources to maintain uninterruptable power supply to the proposed utility of capacity $0.1 \mathrm{~kW}$. The proposed back-up system gets charged from the available reliable RESs with no pollution and noise, and it can also reduce the electricity bill. The proposed intelligent power module functions are displayed on LCD, it has been designed and analyzed in real time environment.
\end{abstract}

Keywords: Battery Storage; Efficiency; Reliability; Renewable Energy Sources; Smart Power Module; Solar PV.

\section{Introduction}

Power is the most important requirement for the entire world. The demand for electricity has been increasing day-by-day and the frequent power cuts is causing serious problems in various areas like banks, hospitals, research labs, etc. Due to limited amount of power generation at power station and due to storage of nonrenewable continuous supply source, it beings a biggest challenge in whole world to effective utilization of the non-renewable energy sources. An important requirement of electric power distribution systems is the need for automatic operation. In particular, the rapid and reliable transfer of the system from one power source to another during certain system events is important to achieving the reliability goals for such systems and the facility serves. However, the design of such an automatic transfer system is all too often considered less important than many other aspects of the overall power system design [1].

The strategic role and policy of generation electricity in the development of an economy has always been appreciated by most developed nations. The power sector provides a platform for economic development, and the electricity has brought about development in all areas of productions and services. Electricity has become indispensable to socio-economic and industrial development of any nation. Using uninterrupted power supply in an automated mode, we always have a substitute arrangement as backup to take place of main power supply in case of power-cut in an emergency case, where the power cut cannot be avoided [2].

Automatic Switching has been a very rapidly growing area of electronics with good potential for further developments. The most attractive applications of this technology are in medium and large scale industries. Every individual is paying money to have a better standby supply has a right to have maximum satisfaction for its industrial needs. Generally inverters are not supposed to be the best choice for backup supply because inverter becomes fail due to insufficient battery time. In order to get rid of this problem, the user will go for stand by generators that are specifically designed to fulfill industrial needs. The main problems of turning it on/off can be removed by installing the auto transfer switch (ATS) for industrial generators. The problems with auto switching circuit for continuous supply are: time delay in switching, low efficiency, high cost tariff, heavy size and high maintenance [3].

In Reference [4], the combination of both the renewable and nonrenewable energy sources are used to get the continuous power supply such as mains, solar, inverter, small diesel generator. The power cut of these sources can be manually done by switches. The continuous supply to load can be given by automatic operation of relay, relay driver IC with the help of arduino microcontroller. References [5]-[6] presented an approach to provide continuous power supply to a load, by selecting the supply from any of the four sources, namely solar, inverter, mains and generator, automatically in case if one the source is absent. The design and analysis of microcontroller based smart battery charger designed in [7], for the multimode operation to ensure no power cut. Reference [8] is aimed at developing a real-time, robust and intelligent grid connected solar panel to provide power to the loads from solar panel at day time, and switch the power to the constant DC sources as soon as the solar power falls below a predefined limit. Reference [9] presents the design and implementation of automatic switching circuits which is used in PLC automation for constructing a workable automatic change-over switch with generator starting/shut down functions.

An automatic switching mechanism that transfer the consumer loads to a power source from the generator in the case of power 
failure in the mains supply is proposed in [10]. Reference [11] presents a practical implementation of a grid interactive photovoltaic (PV) uninterruptible power supply (UPS) system using battery storage and a back up diesel generator. A selected combined topology and a new control scheme are proposed in [12] to control the power sharing between batteries and supercapacitors. Reference [13] aims at the development of the autonomous power supply system based on the energy mix. A hybrid energy system consisting of wind, PV and fuel cell is proposed in [14]. Reference [15] has developed a frame work for solar Net Zero Energy Home systems for a single family household in rural India with retrofitting of two appliances with PMDC motors. A multi-functional intelligent uninterruptible power source (UPS) system for grid composed of a three phase fully controlled rectifier, grid and PV as power source, Lead Acid Battery and an IGBT inverter is proposed in [16]. Reference [17] describes the components of a UPS system and reviews the design requirements necessary for its construction with low cost and ease of maintenance. Reference [18] develops a new Arm chips, a set of new ATmega products (such as ATmega 161, ATmega 162), new Network Interface Controller, TCP/IP protocol suite and other software components. The most widely used adaptive hysteresis band current controller is proposed in [19] for Voltage Source Inverter used in UPS to eliminate harmonics in output voltage and current. Reference [20] deals with power factor correction units suitable for implementation in uninterruptible power supplies.

The main aim of this paper is to provide uninterruptable power supply to the loads from various energy sources, such as solar photovoltaic, AC mains and battery backup system in low tariff and highly efficient way. The main contributions of this paper are:

- Provides uninterruptable power supply to the load from various sources.

- Provides rapid and reliable transfer of the system from one power source to another power source.

- The automatic switching circuits are designed and implemented in real time environment with low cost tariff.

- Provides supply to the load by using both renewable and non renewable sources.

The rest of this paper is organized as follows: The designing criteria, schematic of proposed work with the components required and working principle of the proposed smart uninterrupted power supply is described in Section 2. Section 3 presents the hardware design of the proposed real time module with the experimental setup. The simulation results and discussion is presented in Section 4 Finally, the contributions with concluding remarks are presented in Section 5.

\section{Design of proposed smart uninterrupted power supply}

The proposed intelligent/smart power module is designed in such a way that, initially the load gets supplied from solar energy. This solar energy received from solar panels is stored in the battery using the charge controller section. For the charge controller section, the input terminals are connected to the solar panels and the output terminals are connected to the battery terminals, respectively. Here, an UPS is used to convert this stored DC supply to AC supply. A connection is established between the standby UPS and the battery backup system such that the converted AC supply is given to the load. When the solar energy is unavailable then the load gets supplied automatically from the AC mains. Along with this setup, the supply from $\mathrm{AC}$ mains is also used for charging the battery circuit such that even in the absence of both solar and AC mains source, the backup system supplies power to the load by which the main aim of this paper can be achieved [21-22].

The program for automatic switching of the circuit between these three sources is designed in keil version and is inserted in the microcontroller 8051. Using this microcontroller, the load gets supplied from the available reliable source without any time delay by switching the appropriate relays. A LCD is used to display the status of the supply source from which the load gets supplied. Figure 1 depicts the schematic diagram of proposed real time smart uninterruptable power supply module.

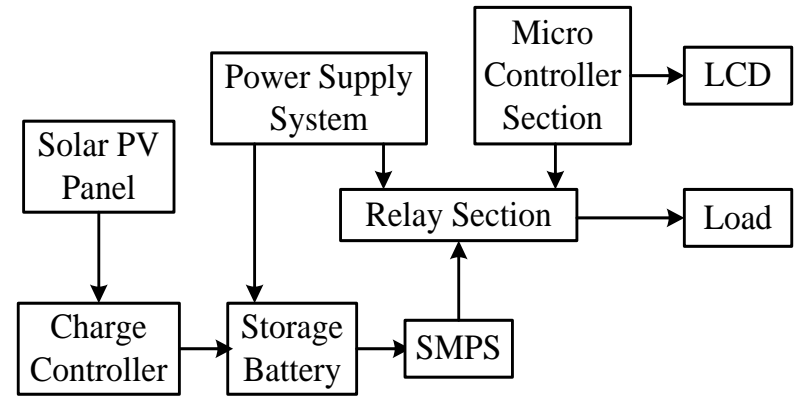

Fig. 1: Schematic Diagram of the Proposed Smart Uninterruptable Power Supply Module.

In the proposed approach, the power supply from the AC mains is given to both the battery backup system and the microcontroller section. For the working of this microcontroller section, it requires $5 \mathrm{~V}$ supply, which can be supplied from power control section. This power supply section contains various components to stepdown the voltage required for the microcontroller [23]. The brief description of the total components and their working principle are explained next:

\subsection{Power supply system}

The power supply system is designed to convert high voltage AC mains electricity to a suitable low voltage supply for the electrical circuits and other devices. A power supply can be broken down into a series of blocks, each of which performs a particular function. A DC power supply which maintains the output voltage constant irrespective of AC mains fluctuations or load variations is known as regulated DC power supply. The $12 \mathrm{~V}$ regulated power supply system used in this paper is depicted in Figure 2.

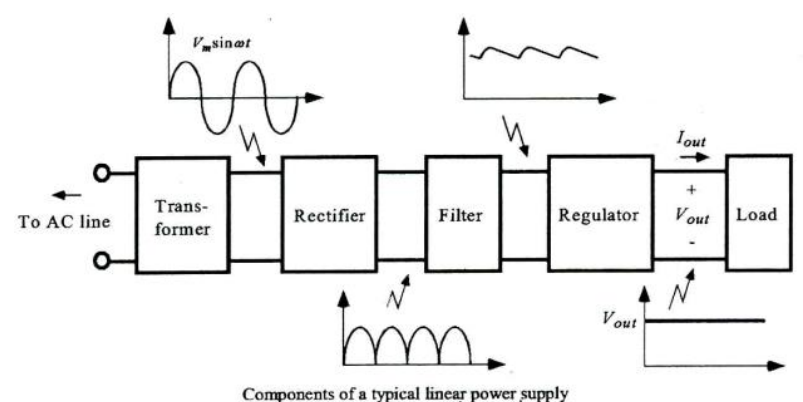

Fig. 2: Schematic Diagram of Power Supply System.

The load in Figure 2 refers to the microcontroller section. This AC mains supply is also connected to the battery backup system for the storage of power. The hardware components in the power supply section are the transformer, rectifier, filter, voltage regulator and the micro-controller. Here, the transformer is used to convert the AC power from one voltage to another voltage with low loss of power [24]. Figure 3 depicts the transformer that is used in this paper. The voltage rating of this transformer is $230 \mathrm{~V} / 12 \mathrm{~V}$.

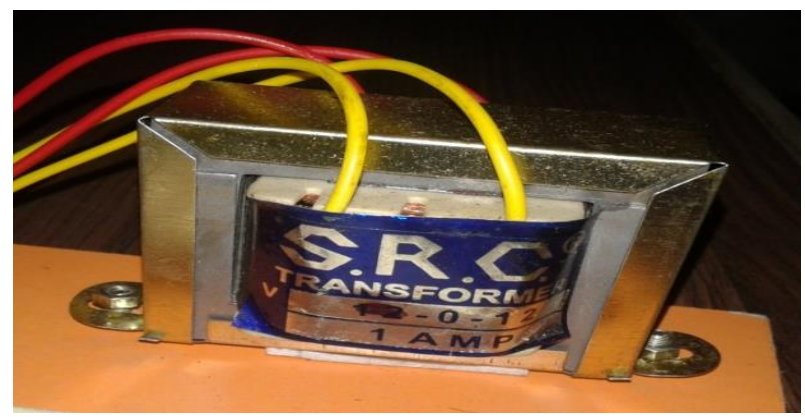


Fig. 3: Transformer Used in the Power Supply Module. Rectifier is used to convert AC to DC, and this process is known as rectification. The bridge type full wave rectifier is used in this paper and it is depicted in Figure 4.

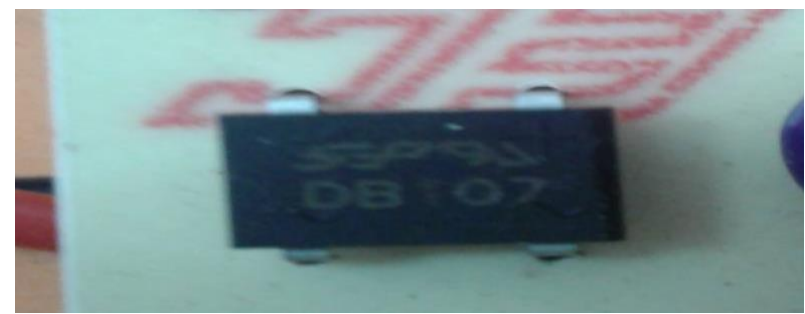

Fig. 4: Bridge Type Rectifier Used in the Power Supply Module.

A Capacitor, in parallel to the load, provides an easier by-pass for the ripples voltage though it due to low impedance at ripple frequency and leaves the DC to appear at the load. The capacitor filter used in this paper is depicted in Figure 5.

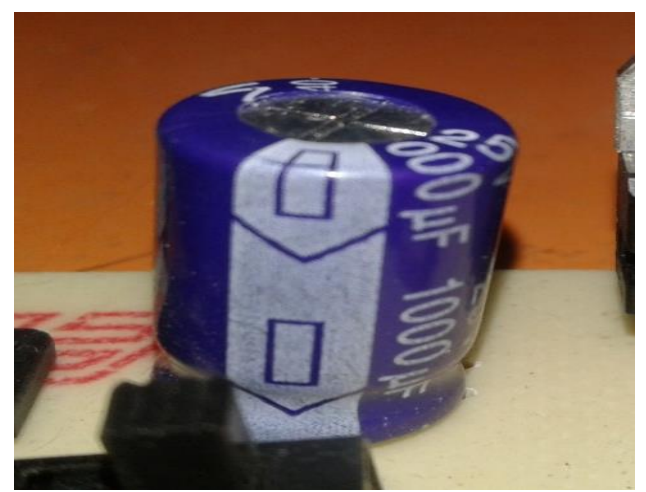

Fig. 5: Capacitor Filter Used in the Power Supply Module.

Filtering is performed by a large value electrolytic capacitor connected across the DC supply to act as a reservoir, supplying current to the output when the varying DC voltage from the rectifier is falling. The capacitor charges quickly near the peak of the varying DC, and then discharges as it supplies current to the output. In this paper, $1000 \mu \mathrm{F}$ capacitor is used. Large value of capacitor is placed to reduce ripples and to improve the DC component. Voltage regulator ICs are available with fixed (typically 5, 12 and $15 \mathrm{~V})$ or variable output voltages [25-26]. Most regulators include some automatic protection from excessive current and overheating. The voltage regulator used in this work is depicted in Figure 6.

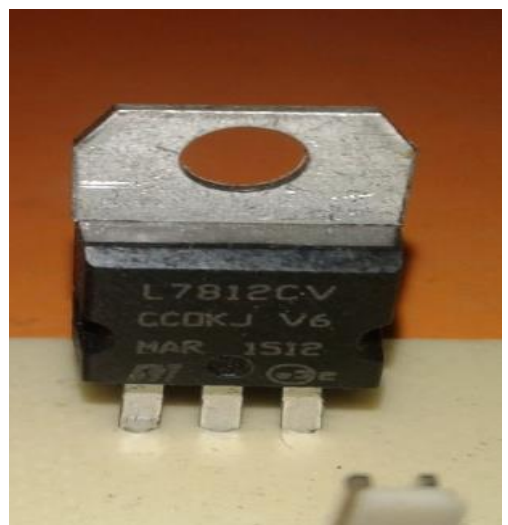

Fig. 6: Three Terminal Voltage Regulator Used in the Power Supply Module.

Most of the fixed voltage regulator IC's have 3 leads and looks like power transistors, such as the $7805+5 \mathrm{~V} 1 \mathrm{~A}$ regulator. The positive lead of unregulated DC power supply is connected to the input pin and the negative lead is connected to the common pin and then when the power supply is turned ON, 12 volts is supplied from the output pin. A microcontroller consists of a powerful CPU tightly coupled with memory, various input/output interfaces such as serial port, parallel port timer or counter, interrupt controller, etc., integrated on to a single silicon chip. It has $4 \mathrm{kB}$ on chip flash memory is used in this paper [27]. The on-chip flash ROM allows the program memory to be reprogrammed in system. In this paper, 8051 microcontroller is used.

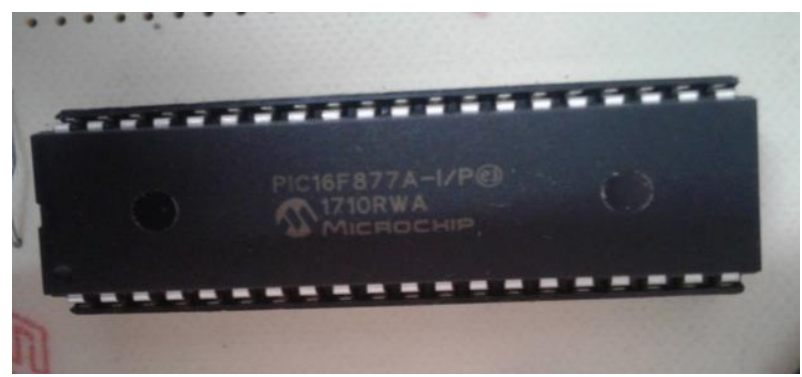

Fig. 7: Microcontroller Used in the Smart Uninterrupted Power Supply System.

There are two buses in 8051 microcontroller one for program and another is for data. As a result, it has two storage rooms for both program and data of $64 \mathrm{~K}$ by 8 size. The microcontroller comprise of 8 bit accumulator $\& 8$ bit processing unit [28]. For 8051 microcontroller, the programming is performed with embedded $\mathrm{C}$ language using Keil software. It also has a number of other 8 bit and 16 bit registers.

\subsection{Hardware components of power module}

The hardware components of the intelligent/smart power module are: solar photovoltaic (PV) panel, charge controller, storage battery, switch-mode power supply (SMPS), and relay section. The solar energy can be harnessed by the use of solar PV panels, or by solar thermal systems, i.e., Concentrated Solar Power (CSP). Figure 8 depicts the solar panel used in this work. The ratings of this work. The ratings of this solar panel used in this work. The ratings of this solar panel are $12 \mathrm{~V}$ and $180 \mathrm{~W}$.

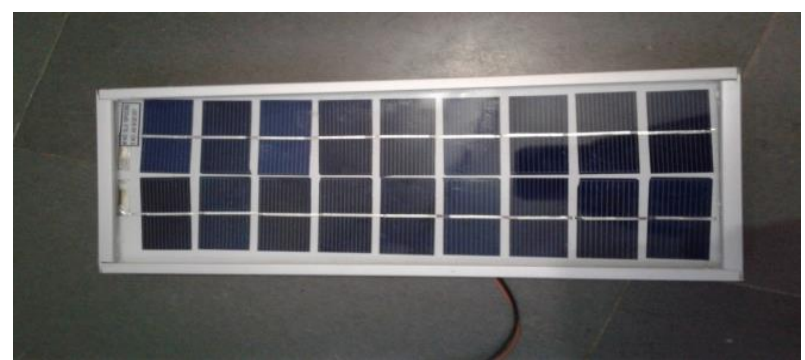

Fig. 8: Solar PV Panel Used in the Smart Uninterrupted Power Supply System.

A charge controller/regulator limits the rate at which electric current is added to or drawn from the electric batteries. It prevents overcharging and may protect against overvoltage, which can reduce battery performance or lifespan, and may pose a safety risk.

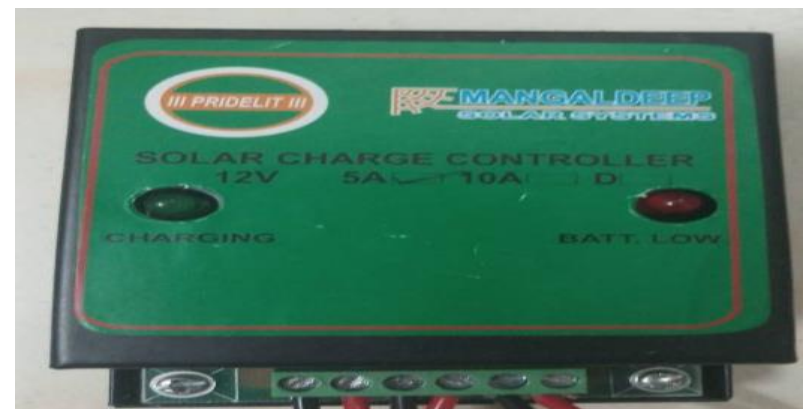

Fig. 9: Charge Controller Used in the Smart Uninterrupted Power Supply System. 
An electric battery consists of one or more electrochemical cells that convert stored chemical energy into electrical energy. A $12 \mathrm{~V}$,

$7 \mathrm{Ah}$ battery is used to run the motor and it is depicted in Figure 10.

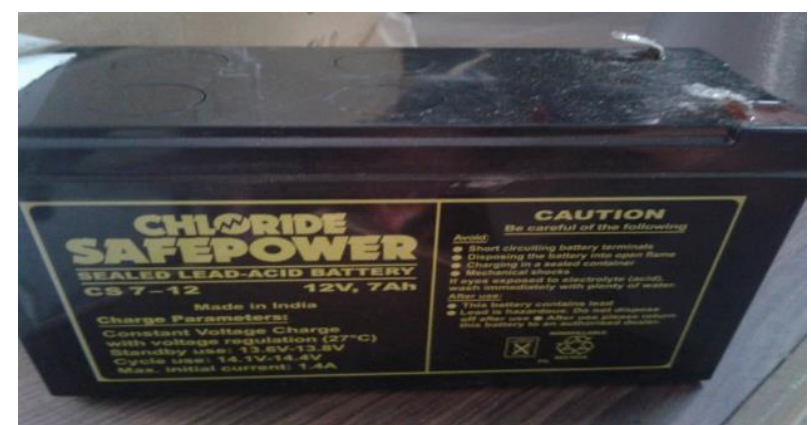

Fig. 10: Storage Battery Used in the Smart Uninterrupted Power Supply System.

\subsection{Working procedure of proposed smart uninter- ruptible power supply}

When the solar energy is available then the load gets supplied from it. If the solar energy is unavailable then immediately the load gets supplied from the next reliable source mains. If both the sources are unavailable then the load gets supplied from the storage battery which is charged from the solar energy and supply mains during their active time [29]. A flow chart resembling the working principle of proposed smart uninterruptible power supply system is depicted in Figure 11.

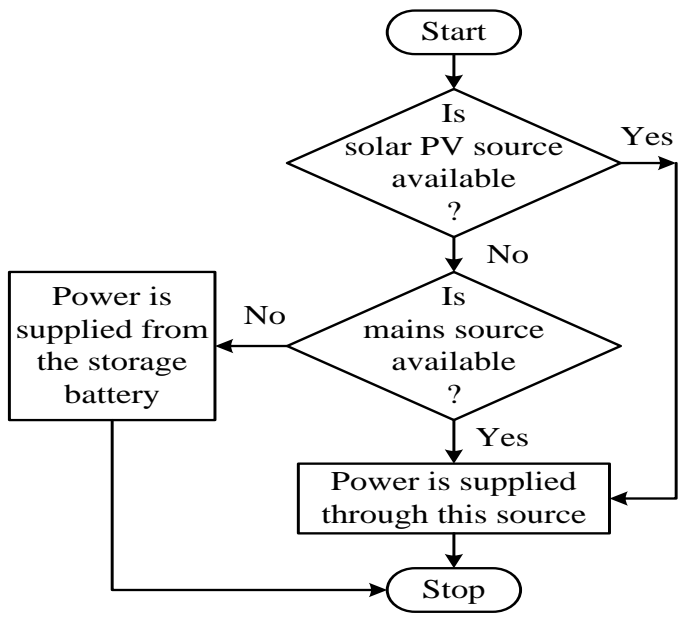

Fig. 11: Flow Chart of Proposed Smart Uninterrupted Power Supply System.

\section{Hardware design and development}

The main contribution of the work is in designing and developing the automatic switching circuit. Automatic switching circuit is designed in such a way that, initially the load gets supplied from reliable source, solar energy where the battery gets charged simultaneously using this solar energy. When the solar energy is unavailable then the load gets supplied from the AC mains while the battery gets charged parallelly using this reliable source. When both the solar and AC mains sources are unavailable then the load gets supplied from the backup power system. The solar panels are connected to the battery using the charge controller. This charge controller regulates the battery charging in its limits. The AC mains are directly connected to the battery section. Using the switched mode power supply (SMPS), the stored energy in backup system is converted into AC and is supplied to the load [28].

The required program for this automatic switching is given to the microcontroller section. This microcontroller section operates the relay section accordingly as per the availability of the proposed reliable sources. A LCD is connected to this microcontroller sec- tion will display the status of supply source. The intelligent/smart power module is designed in such a way that, the solar panel is connected to the storage battery through the charge controller and a direct connection between the $\mathrm{AC}$ mains and battery using relay drive. A $100 \mathrm{~W}$ bulb as load is connected to the module [28-30]. The top view of implemented smart uninterruptible power supply module with solar PV panel, charge controller, SMPS, storage battery, microcontroller and the power supply is depicted in Figure 12. The connections are made in such a way that, uninterruptable power supply is achieved at the load section.

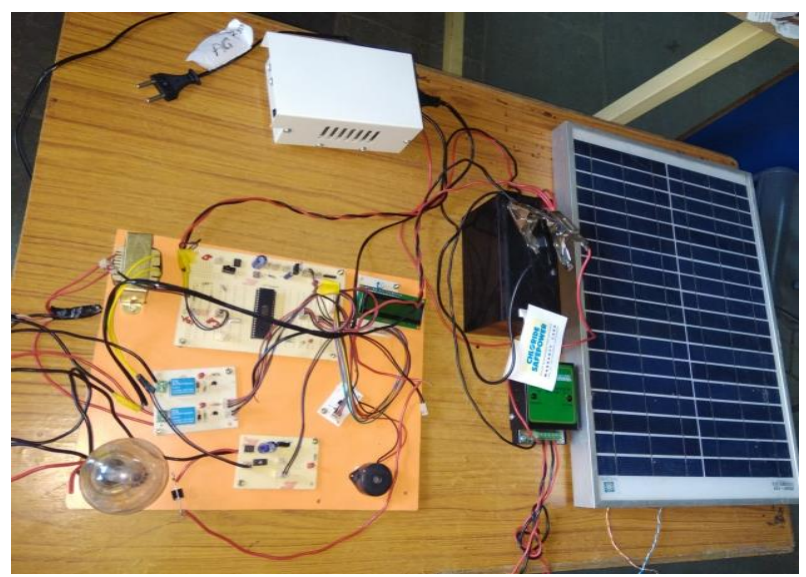

Fig. 12: Top View of Implemented Hardware of Smart Uninterrupted Power Supply System.

The side view of developed intelligent/smart power module is depicted in Figure 13. In this side view, one can observe SMPS, storage battery, solar PV panel, power supply section, microcontroller section, relay section and load section.

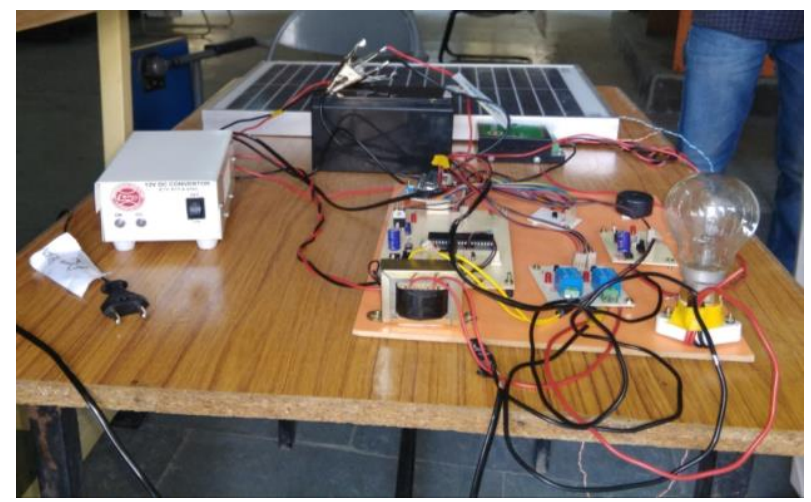

Fig. 13: Side View of Implemented Hardware of Smart Uninterrupted Power Supply System.

\section{Simulation results and discussion}

In this section, the simulation results of the working real time hardware module are presented. Here, the load gets supplied from various sources, such as solar energy, AC mains, supply and backup system. The status of particular operating source is displayed on the LCD. Various simulation results are presented next:

\subsection{Power supply from solar energy}

As the first preference of supply is given to the solar energy, when the smart uninterruptible power supply module is operated then the load gets supplied reliable from solar energy. During the active time of solar energy, the battery gets charged from this energy and the load is in ON position. As the load gets supplied from the solar source, the LCD displaying section displays as "SOLAR CONNECTED". This is as shown in Figure 14. 


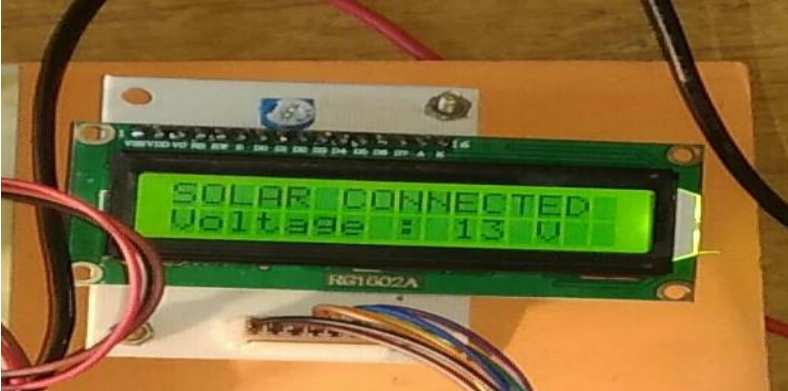

Fig. 14: LCD Section Displaying the Status of the Supply Source.

\subsection{Power supply from $\mathrm{AC}$ mains}

The second preference of supply is given to the AC mains. When the solar energy is unavailable then the load gets supplied from AC mains and eventually the battery gets charged from this reliable source. As the load gets supplied from AC the supply mains, the LCD display section displays as "MAINS CONNECTED" and it is depicted in Figure 15.

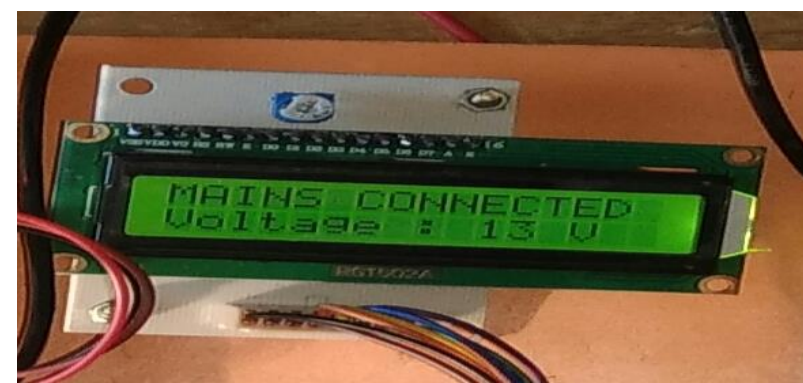

Fig. 15: LCD Displaying the Status of the Supply Source.

\subsection{Power supply from backup system/battery storage}

When both the solar and AC mains sources are unavailable then the load gets supplied from the backup system. This backup system stores the energy from solar energy, AC mains. The stored DC supply from battery is converted into AC supply through SMPS and this is supplied to the load. Table 1 presents various testing conditions of smart uninterrupted power supply system.

Table 1: Various Testing Conditions of Smart Uninterrupted Power Supply System

\begin{tabular}{|c|c|c|c|c|}
\hline \multicolumn{4}{|c|}{ Source Condition } & \multirow[b]{2}{*}{$\begin{array}{l}\text { Load } \\
\text { Status }\end{array}$} \\
\hline $\begin{array}{l}\text { Solar } \\
\text { PV }\end{array}$ & $\begin{array}{l}\text { AC } \\
\text { Mains }\end{array}$ & $\begin{array}{l}\text { Storage Bat- } \\
\text { tery }\end{array}$ & LCD Status & \\
\hline $\mathrm{ON}$ & OFF & $\mathrm{OFF}$ & \multirow{2}{*}{$\begin{array}{l}\text { Solar Connected } \\
\text { Mains Connect- } \\
\text { ed }\end{array}$} & $\mathrm{ON}$ \\
\hline OFF & $\mathrm{ON}$ & OFF & & $\mathrm{ON}$ \\
\hline OFF & OFF & $\mathrm{ON}$ & $\begin{array}{l}\text { Battery Con- } \\
\text { nected }\end{array}$ & $\mathrm{ON}$ \\
\hline
\end{tabular}

In this paper, the practical and the experimental setup for all the supplying sources has been developed. The results and analysis of the working module are tested successfully and verified and explained for various conditions.

\section{Conclusions}

The design and implementation of intelligent/smart power module for uninterruptable power supply module has been discussed in this paper with all its features and details. The significance of this proposed thesis lies in its various advantages and wide places of applications such as industries, hospitals, banks, etc. It has been designed and developed by integrating the features of various hardware components. Presence of every module has been reasoned out and also automatically switch over to next reliable power source and placed carefully thus contributing to the best working of the unit. The proposed concept has been designed, imple- mented and examined effectively for the proposed hardware model for various sources and load conditions and it has been observed that it is reliable, low cost, less weight and requires no maintenance.

\section{Acknowledgments}

This research work is based on the support of "Woosong University's Academic Research Funding - 2018" and "TKR College of Engineering \& Technology's Research Funding".

\section{References}

[1] S. Dudhate, A. Attargekar, D. Desai \& A. Patil (2016), Power Supply Control from Different Sources, International Journal of Scientific \& Engineering Research, vol. 7, no. 1, pp. 484-487.

[2] Y.H. Wen (2011), Renewable Energy/Mains Power Integration Controller and Switching Module, Masters Thesis, University of Canterbury, Christchurch, New Zealand. Available. [Online] https://ir.canterbury.ac.nz/bitstream/handle/10092/5681/thesis_fullt ext.pdf; sequence=1.

[3] S. Vavilapalli, S. Padmanaban, U. Subramaniam \& L. Mihet-Popa (2017), Power Balancing Control for Grid Energy Storage System in Photovoltaic Applications-Real Time Digital Simulation Implementation, Energies, vol. 10, pp. 1-22. https://doi.org/10.3390/en10070928.

[4] A.P. Patil (2017), Auto Power Supply from Different Sources, International Journal of Research in Electrical Engineering, vol. 4, no. 2, pp. 160-162.

[5] S. Dudhate (2016), Power Supply Control from Different Sources, International Journal of Scientific \& Engineering Research, vol. 7, no. 1, pp. 484-487.

[6] R. Thilagavathy, Y. Spoorthi \& H.D. Nalina (2016), Automatic Power Supply Controller By Four Different Sources, $2^{\text {nd }}$ International Conference on Innovative Trends In Engineering, Science and Management, pp. 276-281.

[7] V. Sampath Kumar \& N.K. Tiwari (2015), Automatic Multimode Smart Charger with Power Supply Control to Ensure Uninterrupted Power backup, IPASJ International Journal of Electronics \& Communication (IIJEC), vol. 3, no. 7, pp. 7-10.

[8] M. Verma, H. Agarwal, N. Rawat, V. Kashyap \& A. Kumar (2015), Synchronization Between Solar Panel \& AC Grid Supply For Different Loads, International Journal of Scientific and Technology Research, vol. 4, no. 9, pp, 416-425.

[9] R. Selot \& A. Kumar (2015), A Review of Automatic Switching by Using PLC System, International Journal of Digital Application \& Contemporary Research, vol. 4, no. 3, pp. 1-5.

[10] L.S. Ezema, B.U. Peter, O.O. Harris (2012), Design of Automatic Change Over Switch with Generator Control Mechanism, Academic Research International, Part-I: Natural and Applied Sciences, vol. 3, no. 3, pp. 125-130.

[11] C.V. Nayar, M. Ashari \& W.W.L. Keerthipala (2000), A gridinteractive photovoltaic uninterruptible power supply system using battery storage and a back up diesel generator, IEEE Transactions on Energy Conversion, vol. 15, no. 3, pp. 348-353, Sept. 2000. https://doi.org/10.1109/60.875502.

[12] V.M. Miñambres-Marcos, M.Á. Guerrero-Martínez, F. BarreroGonzález \& M.I. Milanés-Montero (2017), A Grid Connected Photovoltaic Inverter with Battery-Supercapacitor Hybrid Energy Storage, Sensors, vol. 17, pp. 1-18.

[13] W. Fedak, S. Anweiler, R. Ulbrich \& B. Jarosz (2017), The Concept of Autonomous Power Supply System Fed with Renewable Energy Sources, Journal of Sustainable Development of Energy, Water and Environment Systems, vol. 5, no. 4, pp. 579-589.

[14] C. Marisarla \& K. Ravi Kumar (2013), A Hybrid Wind and Solar Energy System with Battery Energy Storage for an Isolated System, International Journal of Engineering and Innovative Technology (IJEIT), vol. 3, no. 3, pp. 99-104.

[15] P. Muthuvel, S.A. Daniel \& D.G. Yazhini (2016), Retrofitting domestic appliances for PV powered DC Nano-grid and its impact on.net zero energy homes in rural India, Engineering Science and Technology, an International Journal, vol. 19, no. 4, pp. 1836-1844.

[16] A. Chaulagain, N. Mainali, S. Dhakal, S. Aryal \& N.R. Karki (2017), Modelling and Simulation of Intelligent UPS for Grid, International Journal of Innovative Research in Science, Engineering and Technology, vol. 6, no. 7, pp. 14502-14514. 
[17] S.S.N. Okeke, C.A. Okeke, B.U. Mortune \& C.C. Okeke (1997), Design criteria for an uninterruptable power source (UPS), Journal of Power Sources, vol. 66, no. 1-2, pp. 151-154.

[18] D. Zhang, D. Dong \& H. Peng (2012), Research on development of embedded uninterruptable power supply system for IOT-based mobile service, Computers \& Electrical Engineering, vol. 38, no. 6, pp. 1377-1387. https://doi.org/10.1016/j.compeleceng.2012.04.001

[19] S. Saraswathy, K. Punitha \& D. Devaraj (2013), Implementation of current control techniques for Uninterruptable Power Supply, International Conference on Circuits, Power and Computing Technologies, Nagercoil, pp. 589-595.

[20] I. Galkin, A. Stepanov \& P. Suskis (2010), Selection of power factor corrector for modular uninterruptable power supply system, Proceedings of 14th International Power Electronics and Motion Control Conference EPE-PEMC 2010, Ohrid, pp. T13-17-T13-21. https://doi.org/10.1109/EPEPEMC.2010.5606807.

[21] S.S. Reddy, J.A. Momoh (2015), Realistic and Transparent Optimum Scheduling Strategy for Hybrid Power System, IEEE Transactions on Smart Grid, vol. 6, no. 6, pp. 3114-3125. https://doi.org/10.1109/TSG.2015.2406879.

[22] S.S. Reddy, J.A. Momoh (2016), Feasibility of Stochastic Voltage/VAr Optimization Considering Renewable Energy Resources for Smart Grid, International Journal of Emerging Electric Power Systems, vol. 17, no. 3, pp. 287-300.

[23] R. Shalini, A.N. Nagashree \& B.G.A. Murthy (2016), Uninterruptable power supply design using Float Cum Boost technology, IEEE International Conference on Power Electronics, Drives and Energy Systems (PEDES), Trivandrum, pp. 1-6. https://doi.org/10.1109/PEDES.2016.7914230.

[24] W. Gengji \& W. Ping (2016), Rotor Loss Analysis of PMSM in Flywheel Energy Storage System as Uninterruptable Power Supply, IEEE Transactions on Applied Superconductivity, vol. 26, no. 7, pp. 1-5. https://doi.org/10.1109/TASC.2016.2594826.

[25] J. Holtz, W. Lotzkat \& K.H. Werner (1986), A high-power multi transistor-inverter uninterruptable power supply system, 17th Annual IEEE Power Electronics Specialists Conference, Vancouver, Canada, 1986, pp. 311-320. https://doi.org/10.1109/PESC.1986.7415576.

[26] S.S. Reddy, Optimal Power Flow with Renewable Energy Resources including Storage, Electrical Engineering, vol. 99, no. 2, pp 685-695. https://doi.org/10.1007/s00202-016-0402-5.

[27] H. Bergsma \& F. Leferink (2015), Using an in-line uninterruptable power supply as TEMPEST 'filter' for naval vessels, IEEE International Symposium on Electromagnetic Compatibility, Dresden, pp. 1106-1110.

[28] S.S. Reddy (2017), Optimization of Renewable Energy Resources in Hybrid Energy Systems, Journal of Green Engineering, vol. 7, pp. 43-60. https://doi.org/10.13052/jge1904-4720.7123.

[29] S.S. Reddy, V. Sandeep, C.M. Jung (2017), Review of Stochastic Optimization Methods for Smart Grid, Frontiers in Energy, vol. 11, no. 2, pp. 197-209.

[30] Y. Zhang, X. Han \& X. Yongquan (2009), Remote Uninterruptable Power Supply Monitoring over GPRS, Third International Symposium on Intelligent Information Technology Application, Nanchang, pp. 557-560. 